\title{
The Financial Development and Economic Growth of Fujian Province \\ Chen Lu
}

Tan Kah Kee College, Xiamen University, Zhangzhou, 363105, China;

luchen@xujc.com

Keywords: Efficiency of financial development; Economic growth; ADF test; Fujian province

\begin{abstract}
By using the data from 1994-2014, this paper analyze the relationship between financial development and local economic growth of Fujian province. Our empirical research show that the financial development plays a promoting role in economic growth, the deeper the degree of financial market development and the higher the efficiency of financial development, the faster the development of the economic market.
\end{abstract}

\section{Introduction}

The relationship between the development of financial sectors and economic growth has been discussed widely and their mutual effect on each other has not come to a consensus. The original paper tackling its relationship was done by Schumpeter (1912) [1]. His main consideration of financial development was focused on its role in promoting technological innovation which enhances economic growth. Robinson (1952) [2] further asserted that the development of financial sector would have no effect on economic growth and also emphasized that the effect should not be overstated. Furthermore, she mentioned that it is the economic growth that promote the development of financial sector.

Following this debate, many scholars continued to show empirically and theoretically the existence of mutual effect on each other. Gurley and Shaw (1960) [3] showed that the positive effect of finance could not be ignored, and their opinion was supported by Mckinnon (1973) [4]. On the other hand, many scholars empirically tested the existence of effect on growth. The pioneering research was done by Goldsmith (1969) [5]. He used the cross-nation data from 1860 to 1963 from 35 countries and his research showed that there is close relationship between financial development and growth, even though the causality effect might not be so clear. Not only that, Levine and Zervos (1998) [6] also proved that the liquidity of stock and the development of banking sector would have positive effect on capital accumulation and productivity in the long run.

Regarding the development of financial sector and its effect on the case of China, many researchers tend to analyze from the national wide. Tan (1999) [7] was the pioneering work on this field. And his research mentioned that there is significantly positive between them. Following that, Liu (2012) [8] and Fan (2014)[9] used different empirical method to analyze its relationship. And their results was different from previous research, indicating that the mutual effect was not so clear.

Different from previous researches, this paper focus on the provincial level consideration of financial development and its effect on local economic growth. Rather than conducting empirical research from the national standpoint, we choose Fujian province and conducted detailed tests and regression. By applying three index covering different sections of financial sector, our research shows that the development of financial sector is Grange reason to local economic growth, but the economic growth does not necessarily lead to the advance of finance sectors.

The next section gives detailed index construction regarding financial development. And after that, we conduct necessary ADF test, co-integration test and Grange causality test. The last section concludes. 


\section{The Index Construction of Financial Development}

By using the data from 1994 to 2014, this paper define three index to measure the development of financial sectors of Fujian province, including the banking and insurance sections of financial sectors. We will give detailed explanation of those three index as follows.

(1) Financial interrelation ratio (FIR) is widely used as an index to measure the development of financial sectors. Specifically, FIR=the sum of credit and deposit/GDP, which means that the higher value of FIR, the higher degree of financial development is.

(2) The second index used is to measure the development of insurance sector. Specifically, the index is named as degree of insurance magnitude (DIM) which is constructed as DIM=insurance revenue/GDP.

(3) Financial allocation efficiency (FAE) is another index to measure the efficiency of financial development. Specifically, FAE=the amount of credit/the amount of deposit. Obviously, this index reveals the ability of financial institutions changing bank deposit into loan and changing saving to investment.

After that, we need to define the index for measuring the growth. And the most widely used index would be GDP. It is worthwhile to note that GDP has two different notations: nominal and real GDP. Since it is common to change nominal GDP into real value when empirical research is done, we in this paper convert the nominal value to real value based on the consumer purchasing index (CPI) in order to eliminate the influence of price on the producing ability of the specific region. Furthermore, we set the 1994 price level as the base year, i.e., the CPI of 1994 is set to be 100. The data we applied in this paper comes from the China Statistic Yearbook and Fujian Statistic Yearbook. As for the data of insurance income, it comes from the website and database of central bank.

\section{The Relationship Between Financial Development and Economic Growth}

The Relationship between FIR and Economic Growth. In this subsection, we test the relationship between financial interrelation ratio and economic growth of Fujian province. In order to do that, the unit-root test should be conducted to test the stability of data. It should be noted that the GDP data and FIR data are carried on a logarithm form. The ADF test results are summarized as follows:

Table 1: ADF Test of LNGDP and LNFIR

\begin{tabular}{|c|c|c|c|c|}
\hline Series & $\begin{array}{c}\text { Test type } \\
(\mathrm{C}, \mathrm{T}, \mathrm{K})\end{array}$ & ADF Value & $\begin{array}{c}5 \% \\
\text { Critical Value }\end{array}$ & Stability \\
\hline LNGDP & $(\mathrm{C}, \mathrm{T}, 1)$ & -2.43 & -3.67 & Unstable \\
\hline D(LNGDP $)$ & $(0,0,1)$ & -3.89 & -2.71 & Stable \\
\hline LNFIR & $(\mathrm{C}, \mathrm{T}, 1)$ & -3.03 & -4.53 & Unstable \\
\hline D $($ LNFIR $)$ & $(\mathrm{C}, 0,1)$ & -5.68 & -3.04 & Stable \\
\hline
\end{tabular}

Note: $\mathrm{C}$ is intercept and $\mathrm{T}$ is the constant value and $\mathrm{K}$ represents lag period. The $\mathrm{D}$ represents that first order differentiation is applied.

It can be seen from Table 1 that the T-statistics of series LNGDP and LNFIR are higher than the specific critical value, which indicates that the null hypothesis cannot be rejected, meaning the possibility of unstable variable series. However, when first order differentiation of those two series is applied, the T-statistics of those two variables are all less than its critical value, and then we can say that LNGDP and LNFIR are first order stable, satisfying the condition for the following co-integration test.

After we finish the ADF test, the co-integration test follows. According to the method of E-G two steps, we firstly do the regression the LNGDP and LNFIR in order to test the existence of co-integration relationship. The regression results is given as 


$$
\begin{aligned}
L N G D P= & 6.6968+3.0923 * L N F I R \\
& (94.49) \quad(26.83)
\end{aligned}
$$

where the values in the basket represent the T-statistics, indicating that both the constant value and the coefficient value are all significant. The F-statistic value is 719.7529 , indicating the whole regression function is significant. From (1), we can tell that the 1\% change of FIR will cause real GDP to increase by $3.0923 \%$.

In order to further analyze the relationship between LNGDP and LNFIR, we then test the causality relationship between those two variables. The Granger test is applied and the results are summarized as:

Table 2: The Grange test of LNGDP and LNFIR

\begin{tabular}{|c|c|c|c|c|}
\hline Null Hyphthesis & Lag period & F statistic & P value & Result \\
\hline LNGDP is not the Grange cause of LNFIR & & 4.33369 & 0.0528 & Accpted \\
\hline LNFIR is not the Grange cause of LNGDP & 1 & 5.51867 & 0.0312 & Rejected \\
\hline
\end{tabular}

The result obtained in the Table 2 reveals that there is 0.0528 probability to accept the fact that the LNGDP is not the Grange cause of LNFIR, indicating that LNGDP is not the reason for LNFIR. Besides that, there is 0.0312 probability for use to reject the null hypothesis under the $5 \%$ significant level that LNFIR is not the Grange cause of LNGDP, indicating the development of FIR would cause higher economic growth.

The Relationship between Development of Insurance Sector and Economic Growth. In this subsection, we test the relationship between financial interrelation ratio and economic growth of Fujian province. In order to do that, the unit-root test should be conducted to test the stability of data. It should be noted that the GDP data and DIM data are carried on a logarithm form. The ADF test results are summarized as follows:

Table 3: ADF Test of LNGDP and LNDIM

\begin{tabular}{|c|c|c|c|c|}
\hline Series & Test type & ADF Value & $5 \%$ Critical Value & Stability \\
\hline LNGDP & $(\mathrm{C}, \mathrm{T}, 1)$ & -2.43 & -3.67 & Unstable \\
\hline D(LNGDP) & $(0,0,1)$ & -3.89 & -2.71 & Stable \\
\hline LNDIM & $(0,0,1)$ & -1.61 & -1.96 & Unstable \\
\hline D(LNDIM) & $(0,0,1)$ & -2.72 & -1.96 & Stable \\
\hline
\end{tabular}

Note: $\mathrm{C}$ is intercept and $\mathrm{T}$ is the constant value and $\mathrm{K}$ represents lag period. The $\mathrm{D}$ represents that first order differentiation is applied.

It can be seen from Table 3 that the T-statistics of series LNGDP and LNDIM are higher than the specific critical value, which indicates that the null hypothesis cannot be rejected, meaning the possibility of unstable variable series. However, when first order differentiation of those two series is applied, the T-statistics of those two variables are all less than its critical value, and then we can say that LNGDP and LNFIR are first order stable, satisfying the condition for the following co-integration test.

After we finish the ADF test, the co-integration test follows. According to the method of E-G two steps, we firstly do the regression the LNGDP and LNFIR in order to test the existence of co-integration relationship. The regression results is given as

$$
L N G D P=16.0288+1.9237 * \text { LNDIM }
$$

where the values in the basket represent the T-statistics, indicating that both the constant value and the coefficient value are all significant. The F-statistic value is 76.4828 , indicating the whole regression 
function is significant. From (2), we can tell that the $1 \%$ change of DIM will cause real GDP to increase by $1.9237 \%$.

In order to further analyze the relationship between LNGDP and LNFIR, we then test the causality relationship between those two variables. The Granger test is applied and the results are summarized as:

Table 4: The Grange test of LNGDP and LNFIR

\begin{tabular}{|c|c|c|c|c|}
\hline Null Hypothesis & Lag period & F statistic & P value & Result \\
\hline \multirow{2nnnyyy}{*}{ LNGDP is not the Grange cause of LNDIM } & \multirow{2}{*}{1} & 0.90024 & 0.3560 & Accepted \\
\cline { 1 - 4 } & & 4.96596 & 0.0396 & Rejected \\
\hline
\end{tabular}

The result obtained in the Table 4 reveals that there is 0.3560 probability to accept the fact that the LNGDP is not the Grange cause of LNFIR, indicating that LNGDP is not the reason for LNFIR. Besides that, there is 0.0396 probability for use to reject the null hypothesis under the $5 \%$ significant level that LNFIR is not the Grange cause of LNGDP, indicating the development of FIR would cause higher economic growth.

The Relationship between Financial Efficiency and Economic Growth. In this subsection, we test the relationship between financial efficiency and economic growth of Fujian province. In order to do that, the unit-root test should be conducted to test the stability of data. It should be noted that the GDP data and FAE data are carried on a logarithm form. The ADF test results are summarized as follows:

Table 5: ADF Test of LNGDP and LNFAE

\begin{tabular}{|c|c|c|c|c|}
\hline Series & $\begin{array}{c}\text { Test type } \\
(\mathrm{C}, \mathrm{T}, \mathrm{K})\end{array}$ & ADF Value & $\begin{array}{c}5 \% \\
\text { Critical Value }\end{array}$ & Stability \\
\hline LNGDP & $(\mathrm{C}, \mathrm{T}, 1)$ & -2.43 & -3.67 & Unstable \\
\hline D(LNGDP $)$ & $(0,0,1)$ & -3.89 & -2.71 & Stable \\
\hline LNFAE & $(0,0,1)$ & -0.78 & -1.96 & Unstable \\
\hline D (LNFAE) & $(0,0,1)$ & -3.10 & -1.96 & Stable \\
\hline
\end{tabular}

Note: $\mathrm{C}$ is intercept and $\mathrm{T}$ is the constant value and $\mathrm{K}$ represents lag period. The $\mathrm{D}$ represents that first order differentiation is applied.

It can be seen from Table 5 that the T-statistics of series LNGDP and LNFAE are higher than the specific critical value, which indicates that the null hypothesis cannot be rejected, meaning the possibility of unstable variable series. However, when first order differentiation of those two series is applied, the T-statistics of those two variables are all less than its critical value, and then we can say that LNGDP and LNFAE are first order stable, satisfying the condition for the following co-integration test.

After we finish the ADF test, the co-integration test follows. According to the method of E-G two steps, we firstly do the regression the LNGDP and LNFAE in order to test the existence of co-integration relationship. The regression results is given as

$$
L N G D P=9.4947+4.5151 * L N F A E
$$

$$
\text { (21.09) (2.37) }
$$

where the values in the basket represent the T-statistics, indicating that both the constant value and the coefficient value are all significant. The F-statistic value is 5.6203, indicating the whole regression function is significant. From (3), we can tell that the 1\% change of FAE will cause real GDP to increase by $4.5151 \%$. 
In order to further analyze the relationship between LNGDP and LNFAE, we then test the causality relationship between those two variables. The Granger test is applied and the results are summarized as:

Table 6: The Grange test of LNGDP and LNFAE

\begin{tabular}{|c|c|c|c|c|}
\hline Null Hypothesis & Lag period & F statistic & P value & Result \\
\hline LNGDP is not the Grange cause of LNFAE & \multirow{2}{*}{4} & 0.9857 & 0.4672 & Accepted \\
\cline { 1 - 4 } LNFAE is not the Grange cause of LNGDP & & 4.8859 & 0.0273 & Rejected \\
\hline
\end{tabular}

The result obtained in the Table 6 reveals that there is 0.4672 probability to accept the fact that the LNGDP is not the Grange cause of LNFAE, indicating that LNGDP is not the reason for LNFAE. Besides that, there is 0.0273 probability for use to reject the null hypothesis under the $5 \%$ significant level that LNFAE is not the Grange cause of LNGDP, indicating the development of financial efficiency would cause higher economic growth.

\section{Summary}

Different from previous researches, this paper focus on the provincial level consideration of financial development and its effect on local economic growth. Rather than conducting empirical research from the national standpoint, we choose Fujian province and conducted detailed tests and regression. By using the data from 1994-2014, this paper focus on the analysis of financial development and local economic growth of Fujian province. Our empirical research showed that the financial development plays a promoting role in economic growth, the deeper the degree of financial market development and the higher the efficiency of financial development, the faster the development of the economic market.

\section{References}

[1] .Schumpeter, J.A. 1912. The Theory of Economic Development. Harvard University Press, Cambridge, MA.

[2] .Robinson, Joan. 1952. The generalization of the general theory. The rate of interest and other essays, London: Macmillan, 67-142.

[3] .Gurley, J.G. and E.S. Shaw, 1960, Money in a theory of finance, Washington, D.C.: The Brookings Institution.

[4] .McKinnon, R., 1973, Money and Capital Economic Development, Washington, D.C., The Brookings Institution.

[5] .Goldsmith, R.N. (1969) Financial Structure and Development. Yale University Press, New Haven.

[6] .Levine Ross, Sara Zervos. 1998. Stock Markets, Banks, and Economic Growth. The American Review . Vol. 12, 465-498.

[7] .Tan Ruyong, 1999. The China's financial development and economic growth, Economic Research (Chinese), Vol. 10, 53-61.

[8] .Liu Weihong, Wang Fan, 2012. The empirical study on the regional development of finance and economic growth, Technology and Industry (Chinese), Vol. 12, 57-60.

[9] .Fan Xuejun, 2014. The Development of Finance and Economic Growth: the Empirical Research on China from 1978-2005. Shanghai People Press. 
[10].Chen Haibo, Wei Xiao, 2013. The empirical study on the upgrading of foreign trade and its effect on the change of economic development method (Chinese), Explore on International Trade, Vol.09. 34-40. 